\title{
Does blood sampling from caudal vessels in fish produce parameter values different from those obtained by heart puncture?
}

\author{
Ivana Mikulíková1, Miroslava Palíková ${ }^{1,2}$, Ivana Papežíková',2, Jana Blahová3, \\ Ivona Toulová ${ }^{1}$, Hana Minářová ${ }^{1,4}$ \\ ${ }^{1}$ University of Veterinary Sciences Brno, Faculty of Veterinary Hygiene and Ecology, \\ Department of Ecology and Diseases of Zoo Animals, Game, Fish and Bees, Brno, Czech Republic \\ ${ }^{2}$ Mendel University in Brno, Faculty of Agronomy, \\ Department of Zoology, Fisheries, Hydrobiology and Apiculture, Brno, Czech Republic \\ ${ }^{3}$ University of Veterinary Sciences Brno, Faculty of Veterinary Hygiene and Ecology, \\ Department of Animal Protection and Welfare and Veterinary Public Health, Brno, Czech Republic \\ ${ }^{4}$ Veterinary Research Institute, Department of Infectious Diseases and Preventive Medicine, Brno, Czech Republic
}

Received August 2, 2021

Accepted October 12, 2021

\begin{abstract}
Analyses of blood samples in ichthyology are of importance for assessment of fish health as well as fish responses to environmental stressors. The measurement results may be affected by multiple factors. This study aimed at assessment of the influence of the blood collection site by comparing dual values of indices measured in samples obtained both from the heart and puncturing caudal vessels in the same fish specimens. Our results revealed that the sampling site did not significantly influence measured variables including haematological indices, the plasma biochemistry profile, acid-base balance parameters and the phagocytic activity. To conclude, for the rainbow trout (Oncorhynchus mykiss) both sampling methods are interchangeable with regard to the above-mentioned indices.
\end{abstract}

Oncorhynchus mykiss, phagocytic activity, haematology, acid-base balance, biochemistry

Fish blood samples are analysed for a wide range of purposes. The results of analyses serve as a valuable source of information on fish health and physiology, presence and impacts of environmental stressors, and thus have become a useful tool for fish welfare assessment (Roche and Bogé 1996; Pikula et al. 2021). A number of more or less invasive sampling techniques for blood collection from the heart, cardiac vessels, dorsal aorta, gill vessels and caudal vessels have been developed and described. These methods use cannulation or puncture of vessels and heart, gill incision and tail ablation (Ikeda et al. 1985; Watson et al. 1989; Lo et al. 2003; Lawrence et al. 2020; Salaah 2020). If needed, sedation or anaesthesia of the fish is the first step of the procedure, using chemical restraint (applied by immersion, intramuscular or intravenous route) or electric current (Muntean and Marcus 2016; Reid et al. 2019; Lawrence et al. 2020).

Values of haematological, plasma biochemical as well as other indices in fish always need to be interpreted with respect to extrinsic and intrinsic factors such as the season, photoperiod, species, reproductive cycle, sex, age, diet etc., as these significantly influence their levels (Claus et al. 2008; Ahmed et al. 2020). Pre-sampling manipulation with the fish (capture, transport, anaesthesia), the choice of anticoagulant, handling and storage time of blood samples affect the analysed indices, too (Di Marco et al. 1999; Clark et al. 2011; Maqbool et al. 2014; Fazio et al. 2017; Young et al. 2019).

The choice of an appropriate blood sampling method is influenced by many factors, e.g. by the size and body shape of the fish, desirable sample volume, stability of measured indices, demand for repeated sampling, and intended fate of the fish. In some methods, the blood

Address for correspondence:

MVDr. Ivana Mikulíková, Ph.D.

Department of Ecology and Diseases of Zoo Animals, Game, Fish and Bees

Faculty of Veterinary Hygiene and Ecology

Phone: +420541562654

University of Veterinary Sciences Brno 
draw is conditioned by euthanasia of the fish (Allen 1994; Pedroso et al. 2012). Among commonly used sampling methods are puncture of caudal vessels and heart (Bojarski et al. 2018; Modra et al. 2020; Pikula et al. 2021). Despite the fact that heart puncture provides pure venous blood and caudal puncture provides usually a mixture of venous and arterial blood, the sampling procedure is not unified. When comparing values of indices determined in blood samples obtained by different techniques, it is necessary to take into consideration whether they may have been influenced significantly by the sampling site. The aim of our study was to compare haematological indices, plasma biochemistry profile, acid-base balance parameters and phagocytic activity determined in samples obtained by puncture of caudal vessels and the heart of rainbow trout.

\section{Materials and Methods}

Ethical statement

The experiment was carried out in accordance with national legislation, specifically Act No. 246/1992 Coll., on the Protection of Animals against Cruelty, as amended. The experimental procedures were reviewed and approved by the Animal Care Committee of Mendel University in Brno and by the Ministry of Education, Youth and Sports (MSMT-6675/2018-3).

Animals and procedure

The experiment was carried out in the experimental facility of the Department of Zoology, Fisheries, Hydrobiology and Apiculture, Mendel University in Brno, Czech Republic. Twenty specimens of rainbow trout of weight $375 \pm 125 \mathrm{~g}$, length $310 \pm 27 \mathrm{~mm}$ were used for the study. The fish were removed from water, stunned by a blow to the head and the blood was immediately collected using heparinised syringes, with 50 IU of heparin sodium salt per one $\mathrm{ml}$ of blood (Heparin Léčiva, Zentiva, Prague, Czech Republic). To assess the effect of the sampling technique on selected indices, blood was obtained from each fish via both caudal and heart punctures. The duration of individual sampling procedures did not exceed $15 \mathrm{~s}$, thus blood was not collected later than $80 \mathrm{~s}$ after the stunning of the fish.

Blood samples of ten individuals (obtained by both techniques) were instantly investigated by an i-STAT portable clinical analyser for veterinary use (EC8+ diagnostic cartridge based on electrochemical sensing technologies; Abaxis, USA) to measure sodium, potassium, chloride, total dissolved carbon dioxide, $\mathrm{pH}$, partial dissolved carbon dioxide, bicarbonate, base excess, and anion gap. The i-STAT is a handheld device that allows simultaneous measurement of many blood indices within $2 \mathrm{~min}$, using $60 \mu \mathrm{l}$ of whole blood.

Blood smears, haemoglobin and haematocrit determination (Svobodová et al. 2012) were made promptly after blood collection, a portion of blood was centrifuged to obtain plasma (at $\left.4{ }^{\circ} \mathrm{C}, 800 \times \mathrm{g}, 10 \mathrm{~min}\right)$ and transported together with the remaining portion of the blood samples in a portable cooling box to the laboratories of the University of Veterinary Sciences Brno (Czech Republic) for further assessment of haematological indices, measurement of phagocytic activity, and determination of selected biochemical indices in plasma. Haematological indices determined (Svobodová et al. 2012) included the red blood cell count, mean corpuscular volume, mean corpuscular haemoglobin, mean corpuscular haemoglobin concentration, white blood cell count and the lymphocytes to phagocytes ratio. The ratio was determined using stained blood smears (Svobodová et al. 2012).

The following indices were determined photometrically in plasma using biochemical analyser Konelab 20i and commercial kits (Biovendor, Brno, Czech Republic): glucose, total protein, albumin, triacylglycerols, cholesterol, creatinine, alanine aminotransferase, aspartate aminotransferase, alkaline phosphatase, creatine kinase, lactate, lactate dehydrogenase, ammonia, phosphorus and calcium.

Respiratory burst activity (as a measure of phagocytic activity) was assessed using chemiluminescence enhanced by luminol (Sigma-Aldrich Merck KGaA, Darmstadt, Germany). The reaction mixture contained $50 \times$ diluted blood in Hank's balanced salt solution, luminol dissolved in borate buffer and Zymosan A (Sigma-Aldrich Merck KGaA, Darmstadt, Germany) opsonised by incubation with fish serum as an activator. The final concentration of Zymosan A in the reaction mixture was $0.25 \mathrm{mg} / \mathrm{ml}$ (Papezikova et al. 2016). Chemiluminescence kinetics were measured for 90 min using a Cytation 3M reader (BioTek Instruments, Inc., Winooski, VT, USA). The results were expressed as time of the maximum respiratory burst intensity (peak time), total intensity of respiratory burst defined as the integral of the reaction curve area, maximum respiratory burst intensity (peak), and both maximum respiratory burst intensity and the integral of the reaction curve area adjusted to 1000 phagocytic cells.

As one of the blood samplings was not finished within $80 \mathrm{~s}$ after stunning the fish and one sample analysis performed by i-STAT did not yield results, both heart and caudal puncture data of the specimens were excluded from the study. Therefore, phagocytic activity, haematological, and plasma biochemical incides were measured in 19 heart/caudal puncture samples and 9 heart/caudal puncture data analysed by i-STAT data were used for the study. 
Statistical analysis

Statistical evaluation was performed using the Unistat for Excel 6.5 software. At first, all data were tested for normal distribution by Shapiro-Wilk test. Differences between heart and caudal vessels puncture were tested using paired $t$-test for normally distributed data and Wilcoxon signed-rank test for data with non-normal distribution. Level of significance was set at $P<0.05$. Data are presented as mean values \pm standard deviation.

\section{Results}

Statistical analysis did not reveal any significant differences between samples obtained by puncture of heart and caudal vessels in any tested indicator including haematological indices, plasma biochemistry profile, acid-base balance parameters and phagocytic activity (Tables 1, 2).

\section{Discussion}

Lawrence et al. (2018) recommend blood sampling in teleost fishes to be limited to less than $2 \mathrm{~min}$ to ensure that samples are representative of baseline conditions. The results of haematological and biochemical analysis have been reported to be affected by the method of blood collection. Contamination with enzymes and other constituents from surrounding tissues is considered to be the main source of error (Ikeda et al. 1985). The choice of sampling method is to some extent dependent also on personal preferences and experience of the sampler. Heart blood sampling has been described as demanding in terms of technique and experience (Ikeda et al. 1985), but also as an easier and faster method than caudal vein puncture, enabling more blood to be obtained in a shorter time (Bojarski et al. 2018). Lawrence et al. (2020) refer to caudal puncture as quick and, if done properly, having minimal impacts on the welfare of the fish. According to Clark et al. (2011) blood sampled rapidly (142 $\pm 26 \mathrm{~s}$ ) using the caudal puncture technique provides an accurate representation of the properties of the circulating blood prior to capture. The technique has also been adapted for small fish, so that e.g., zebrafish

Table 1. Haematological indices and phagocytic activity of rainbow trout samples obtained by blood collection from the heart and caudal vessels, $\mathrm{n}=19$.

\begin{tabular}{llccr}
\hline Indicator & Units & $\begin{array}{c}\text { Sampling from the heart } \\
\text { mean } \pm \text { standard deviation }\end{array}$ & $\begin{array}{c}\text { Sampling from the caudal vessels } \\
\text { mean } \pm \text { standard deviation }\end{array}$ & $P$ \\
\hline $\mathrm{RBC}$ & $10^{12} / 1$ & $1.00 \pm 0.24$ & $1.05 \pm 0.25$ & 0.36 \\
$\mathrm{Ht}$ & $1 / 1$ & $0.38 \pm 0.08$ & $0.40 \pm 0.08$ & 0.13 \\
$\mathrm{Hb}$ & $\mathrm{g} / 1$ & $67.04 \pm 15.78$ & $68.55 \pm 15.83$ & 0.32 \\
$\mathrm{MCV}$ & $\mathrm{fl}$ & $394.93 \pm 68.46$ & $386.06 \pm 38.86$ & 0.62 \\
$\mathrm{MCH}$ & $\mathrm{pg}$ & $68.23 \pm 10.72$ & $65.92 \pm 6.99$ & 0.39 \\
$\mathrm{MCHC}$ & $1 / 1$ & $0.17 \pm 0.02$ & $0.17 \pm 0.01$ & 0.20 \\
WBC & $10^{9} / 1$ & $33.00 \pm 12.38$ & $29.16 \pm 9.59$ & 0.14 \\
Lymphocytes & $\%$ & $95.63 \pm 3.72$ & $95.32 \pm 4.74$ & 0.79 \\
Phagocytes & $\%$ & $4.37 \pm 3.72$ & $4.68 \pm 4.74$ & 0.79 \\
PA peak time & min & $66.63 \pm 14.99$ & $70.50 \pm 15.01$ & 0.14 \\
PA integral & RLU.min & $83291.21 \pm 197663.29$ & $46335.08 \pm 50841.64$ & 1.00 \\
PA peak & RLU & $1460.18 \pm 3207.43$ & $885.03 \pm 956.91$ & 0.95 \\
PA integra/1000 ph. & RLU.min & $1843.51 \pm 1162.06$ & $2253.30 \pm 1899.83$ & 0.28 \\
PA peak/1000 ph. & RLU & $34.22 \pm 19.83$ & $42.71 \pm 34.33$ & 0.35 \\
\hline
\end{tabular}

RBC - red blood cell count; Ht - haematocrit; Hb - haemoglobin; MCV - mean copuscular volume; $\mathrm{MCH}$ - mean corpuscular haemoglobin; $\mathrm{MCHC}$ - mean corpuscular haemoglobin concentration; WBC - white blood cell count; PA - phagocytic activity; ph. - phagocytes; RLU - relative light unit; $P$ - probability value 
Table 2. Plasma biochemical indices and parameters of blood acido-base balance of rainbow trout samples obtained by blood collection from the heart and caudal vessels, $\mathrm{n}=19$.

\begin{tabular}{|c|c|c|c|c|}
\hline Indicator & Unit & $\begin{array}{l}\text { Sampling from the heart } \\
\text { mean } \pm \text { standard deviation }\end{array}$ & $\begin{array}{c}\text { Sampling from the caudal vessels } \\
\text { mean } \pm \text { standard deviation }\end{array}$ & $P$ \\
\hline Total protein & $\mathrm{g} / 1$ & $43.56 \pm 5.66$ & $43.71 \pm 5.26$ & 0.84 \\
\hline Albumin & $\mathrm{g} / 1$ & $12.54 \pm 3.12$ & $12.22 \pm 3.19$ & 0.54 \\
\hline Ammonia & $\mu \mathrm{mol} / 1$ & $565.87 \pm 100.44$ & $551.47 \pm 116.78$ & 0.56 \\
\hline ALP & $\mu \mathrm{kat} / \mathrm{l}$ & $3.64 \pm 1.45$ & $3.37 \pm 1.15$ & 0.21 \\
\hline ALT & $\mu \mathrm{kat} / \mathrm{l}$ & $0.50 \pm 0.42$ & $0.41 \pm 0.30$ & 0.09 \\
\hline AST & $\mu \mathrm{kat} / \mathrm{l}$ & $7.09 \pm 2.53$ & $6.92 \pm 2.09$ & 0.81 \\
\hline $\mathrm{LDH}$ & $\mu \mathrm{kat} / \mathrm{l}$ & $17.01 \pm 15.57$ & $20.3805 \pm 17.47$ & 0.29 \\
\hline CK & $\mu \mathrm{kat} / 1$ & $71.63 \pm 55.40$ & $81.53 \pm 45.22$ & 0.10 \\
\hline Triglycerides & $\mathrm{mmol} / 1$ & $2.85 \pm 1.74$ & $2.92 \pm 1.72$ & 0.89 \\
\hline Cholesterol & $\mathrm{mmol} / \mathrm{l}$ & $7.41 \pm 1.50$ & $7.6784 \pm 1.50$ & 0.32 \\
\hline Glucose & $\mathrm{mmol} / 1$ & $3.61 \pm 1.00$ & $3.37 \pm 0.91$ & 0.06 \\
\hline Lactate & $\mathrm{mmol} / \mathrm{l}$ & $3.52 \pm 2.05$ & $3.53 \pm 1.93$ & 0.95 \\
\hline Creatinin & $\mu \mathrm{mol} / 1$ & $20.68 \pm 5.56$ & $20.50 \pm 4.29$ & 0.84 \\
\hline Calcium & $\mathrm{mmol} / \mathrm{l}$ & $2.87 \pm 0.23$ & $2.94 \pm 0.17$ & 0.17 \\
\hline Phosphorus & $\mathrm{mmol} / \mathrm{l}$ & $5.51 \pm 0.62$ & $5.68 \pm 0.68$ & 0.16 \\
\hline Sodium & $\mathrm{mmol} / \mathrm{l}$ & $144.22 \pm 3.19$ & $143.89 \pm 2.42$ & 0.78 \\
\hline Potassium & $\mathrm{mmol} / \mathrm{l}$ & $3.86 \pm 1.48$ & $3.32 \pm 0.69$ & 0.55 \\
\hline Chloride & $\mathrm{mmol} / \mathrm{l}$ & $131.44 \pm 2.65$ & $130.11 \pm 2.93$ & 0.06 \\
\hline $\mathrm{pH}$ & & $7.03 \pm 0.07$ & $7.03 \pm 0.08$ & 0.93 \\
\hline $\mathrm{tCO}_{2}$ & $\mathrm{mmol} / \mathrm{l}$ & $8.22 \pm 1.56$ & $8.11 \pm 1.83$ & 1.0 \\
\hline $\mathrm{pCO}_{2}^{2}$ & $\mathrm{kPa}$ & $3.70 \pm 0.58$ & $3.59 \pm 0.52$ & 0.53 \\
\hline $\mathrm{HCO}_{3}^{-}$ & $\mathrm{mmol} / \mathrm{l}$ & $7.43 \pm 1.45$ & $7.23 \pm 1.67$ & 0.55 \\
\hline $\mathrm{BE}$ & $\mathrm{mmol} / \mathrm{l}$ & $-23.33 \pm 2.18$ & $-23.56 \pm 2.88$ & 0.80 \\
\hline anGAP & $\mathrm{mmol} / \mathrm{l}$ & $8.67 \pm 3.74$ & $9.67 \pm 3.24$ & 0.39 \\
\hline
\end{tabular}

ALP - alkaline phosphatase; ALT - alanine aminotransferase; AST - aspartate aminotransferase; LDH - lactate dehydrogenase; $\mathrm{CK}$ - creatine kinase; $\mathrm{pH}$ - potential of hydrogen; $\mathrm{tCO}_{2}$ - total dissolved carbon dioxide; $\mathrm{pCO}_{2}$ - partial dissolved carbon dioxide; $\mathrm{HCO}_{3}{ }^{-}$- bicarbonate; $\mathrm{BE}$ - base excess; anGAP - anion gap; $P$ - probability value

Danio rerio can be sampled in a non-lethal manner and even repeated sampling is feasible. Heart puncture of adult zebrafish (heart size 1-2 $\mathrm{mm}$ ) requires a very high level of accuracy (Zang et al. 2013, 2015). Despite the popularity of sampling by caudal puncture, it is not optimal for all fish species (Argungu et al. 2017).

Samples collected by heart puncture contain solely venous blood, while the likelihood of obtaining a sample consisting entirely of venous blood from a caudal peduncle is rather low (Cooke et al. 2019). It is likely that blood is obtained from both arterial and venous vasculature because the two vessels are in proximity to each other. As such, caution is required when this technique is used for determining indices which differ between the two subdivisions of the circulatory system. For this reason, caudal puncture is not ideal for measuring partial pressures of respiratory gases (e.g., $\mathrm{O}_{2}$ and $\mathrm{CO}_{2}$ ) because gas levels differ markedly between veins and arteries (Lawrence et al. 2020). However, Mandelman and Skomal (2009) refer to studies on both large pelagic teleosts and elasmobranchs which found no significant difference in $\mathrm{pH}$ and $\mathrm{pCO}_{2}$ values between arterial and venous blood. In our study, no significant differences were detected in the variables of acid-base balance analysed in heart blood samples and caudal puncture samples. Lawrence et al. (2020) reported that the venous-arterial mixture is unimportant for other variables commonly 
measured in fish blood such as circulating proteins, steroide hormones, triacylglycerols and ions, as they are presumably homogenous in their concentrations throughout the circulatory system, which is in accordance with our results.

During caudal blood sampling from common carp (Cyprinus carpio), Bojarski et al. (2021) observed a higher number of blood clots in cases when fish had been previously subjected to heart puncture. In the fish whose blood was taken first from the caudal vessels (authors refer to caudal vein) and then from the heart, the number of clots was much lower. In our study on rainbow trout, we did not encounter any problem of blood clotting.

Congleton and laVoie (2001) reported higher activities of alanine aminotransferase, aspartate aminotransferase and lactate dehydrogenase and higher potassium concentrations in samples taken by heart puncture compared to samples drawn by caudal vessel puncture, but significantly lower estimates for calcium ions, triacylglycerols, and creatine kinase activity in chinook salmon Oncorhynchus tshawytscha. The two methods produced similar levels of sodium and chloride ions, glucose, total protein, cholesterol, and alkaline phosphatase activity. The authors conlude that caudal vessel puncture should be preferred for blood chemistry studies on juvenile salmonids. Marino et al. (2001) investigated the effect of sampling procedures on serum cortisol, glucose, total protein, osmolality, sodium, chloride, potassium and calcium concentrations in sea bass Dicentrarchus labrax. The site of blood withdrawal (cardiac sinuses/caudal vein) had no effect on the concentration of analysed blood constituents, except for potassium level which was lower in fish bled by heart puncture.

In the study of Bojarski et al. (2018) comparing haematological values of common carp collected from the heart and caudal vessels (authors refer to caudal vein), were revealed significantly higher values of haematocrit, haemoglobin, and erythrocyte count in the latter samples, whereas the leukocyte and thrombocyte counts, percentage of lymphocytes and neutrophils did not differ significantly. In another study, Bojarski et al. (2021) detected a higher erythrocyte count in blood of common carp sampled by caudal puncture compared to heart puncture, whereas haematocrit, mean corpuscular volume, mean corpuscular haemoglobin, total protein and magnesium concentrations were higher in heart blood samples. This was observed in fish subjected first to caudal and then immediately to heart puncture. No significant differences we found in the leucocyte count, differential leukocyte count or erythrocyte morphology based on stained blood smears. The fish subjected first to heart and then to caudal puncture did not show any differences in analysed variables (biochemical analysis included glucose, total protein, cholesterol, calcium, and magnesium).

Our study is the first one to assess the influence of sampling site on respiratory burst activity in fish phagocytes. Similar as for the other analysed variables, we did not detect any such influence. Lo et al. (2003) evaluated the effect of dorsal aorta cannulation on grouper Epinephelus malabaricus including total red and white blood cell counts and phagocytosis. Cannulated fish un/treated with oxytetracycline were compared to fish un/treated with oxytetracycline subjected to caudal puncture. From day 7 to 13, counts of erythocytes and leucocytes of oxytetracycline-treated, cannulated groupers were significantly different from those subjected to caudal vessel puncture. Oxytetracycline treatment improved the phagocytic index of groupers subjected to caudal vessel puncture, but the phagocytic index was lower than that of groupers subjected to cannulation.

To conclude, comparison of literature data indicates that the overall predictability of the sampling site's effect on blood indices in fish is rather low. The results presented in the current study show that data obtained by heart and caudal punctures in rainbow trout are very similar. However, we cannot exclude that the choice of sampling site could be significant for indices which were not analysed in this study. Further study should be performed in order to assess the effect of the sampling site on e.g. indices of oxidative stress. 


\section{Acknowledgements}

The study was supported by FVHE/Pikula/ITA2021.

\section{References}

Ahmed I, Reshi QM, Fazio F 2020: The influence of the endogenous and exogenous factors on hematological parameters in different fish species: a review. Aquac Int 28: 869-899

Allen P 1994: Evaluation of a technique for sampling blood from small fishes. Comp Biochem Physiol 107A: 413-418

Argungu LA, Siraj SS, Christianus A, Amin MSN, Daud SK, Abubakar MS, Abubakar IA, Aliyu-Paiko M. 2017 : A simple and rapid method for blood collection from walking catfish, Clarias batrachus (Linneaus, 1758). Iran J Fish Sci 16: 935-944

Bojarski B, Kondera E, Witeska M, Lugowska K 2018: Differences in hematological values of common carp between cardiac and venous blood. Bull Eur Assoc Fish Pathol 38: 234-239

Bojarski B, Socha M, Drąg-Kozak E, Rombel-Bryzek A, Kapinos S, Szała L, Kondera E, Ługowska K, Witeska M 2021: Does the site of blood collection in fish affect haematological and blood biochemical results? Folia Biol (Krakow) 69: 51-56

Clark TD, Donaldson MR, Drenner SM, Hinch SG, Patterson DA, Hills J, Ives V, Carter JJ, Cooke SJ, Farrell AP 2011: The efficacy of field techniques for obtaining and storing blood samples from fishes. J Fish Biol 79: 1322-1333

Clauss TM, Dove AD, Arnold JE 2008: Hematologic disorders of fish. Vet Clin North Am Exot Anim Pract 11: 445-462

Congleton JL, la Voie WJ 2001: Comparison of blood chemistry values for samples collected from juvenile chinook salmon by three methods. J Aquat Anim Health 13:168-172

Cooke SJ, Lawrence MJ, Raby GD, Teffer AK, Jeffries KM, Danylchuk AJ, Clark TD 2019: Comment: Practices for drawing blood samples from teleost fish. N Am J Aqua 81: 424-426

Di Marco P, McKenzie DJ, Mandich A, Bronzi P, Cataldi E, Cataudella S 1999: Influence of sampling conditions on blood chemistry values of Adriatic sturgeon Acipenser naccarii (Bonaparte, 1836). J Appl Ichthyol 15: 73-77

Fazio F, Ferrantelli V, Saoca C, Giangrosso G, Piccione G 2017: Stability of haematological parameters in stored blood samples of rainbow trout Oncorhynchus mykiss (Walbaum, 1792). Vet Med (Praha) 62: 401-405

Ikeda M, Tsuda S, Kurawaka K, Fukao R, Shirasu Y 1985: Blood sampling from the Cuvierian duct of red sea bream (Chrysophrys major) for hematology and blood biochemistry in toxicological studies. Jpn J Vet Sci 47: 951-955

Lawrence MJ, Jain-Schlaepfer S, Zolderdo AJ, Algera DA, Gilmour KM, Gallagher AJ, Cooke SJ 2018: Are 3 minutes good enough for obtaining baseline physiological samples from teleost fish? Can J Zool 96: 774-786

Lawrence MJ, Raby GD, Teffer AK, Jeffries KM, Danylchuk AJ, Eliason EJ, Hasler CT, Clark TD, Cooke SJ 2020: Best practices for non-lethal blood sampling of fish via the caudal vasculature. J Fish Biol 97: 4-15

Lo WY, Chang CF, Song YL 2003: Evaluation of dorsal aorta cannulation for immunological studies of grouper (Epinephelus malabaricus). Fish Shellfish Immunol 14: 289-303

Mandelman JW, Skomal GB 2009: Differential sensitivity to capture stress assessed by blood acid-base status in five carcharhinid sharks. J Comp Physiol B 179: 267-277

Maqbool A, Ahmed I, Sheikh ZA 2014: Effects of two commonly used anticoagulants on haematology and erythrocyte morphology of rainbow trout (Oncorhynchus mykiss). Int J Fish Aquat Stud 2: 239-243

Marino G, Di Marco P, Mandich A, Finoia MG, Cataudella S 2001: Changes in serum cortisol, metabolites, osmotic pressure and electrolytes in response to different blood sampling procedures in cultured sea bass (Dicentrarchus labrax L.). Appl Ichthyol 17: 115-120

Modra H, Palikova M, Hyrsl P, Bartonkova J, Papezikova I, Svobodova Z, Blahova J, Mares J 2020: Effects of trichothecene mycotoxin T-2 toxin on haematological and immunological parameters of rainbow trout (Oncorhynchus mykiss). Mycotoxin Res 36: 319-326

Muntean V, Marcus I 2016: Techniques of anesthesia and blood sampling in fish. Rev Rom Med Vet 26: 53-59

Papezikova I, Mares J, Vojtek L, Hyrsl P, Markova Z, Simkova A, Bartonkova J, Navratil S, Palikova M 2016: Seasonal changes in immune parameters of rainbow trout (Oncorhynchus mykiss), brook trout (Salvelinus fontinalis) and brook trout $\times$ Arctic charr hybrids (Salvelinus fontinalis $\times$ Salvelinus alpinus alpinus). Fish Shellfish Immunol 57: 400-405

Pedroso GL, Hammes TO, Escobar TD, Fracasso LB, Forgiarini LF, da Silveira TR 2012: Blood collection for biochemical analysis in adult zebrafish. J Vis Exp 63: e3865

Pikula J, Pojezdal L, Papezikova I, Minarova H, Mikulikova I, Bandouchova H, Blahova J, Bednarska M, Mares J, Palikova M 2021: Carp edema virus infection is associated with severe metabolic disturbance in fish. Front Vet Sci 8: 679970

Reid C, Vandergoot C, Midwood J, Stevens D, Bowker J, Cooke S 2019: On the electroimmobilization of fishes for research and practice: opportunities, challenges, and research needs. Fisheries 44: 576-585

Roche H, Bogé G 1996: Fish blood parameters as a potential tool for identification of stress caused by environmental factors and chemical intoxication. Mar Environ Res 41: 27-43 
Salaah SM 2020: An innovative approach to blood collection from fish. J Mari Scie Res Ocean 3: 121-122

Svobodová Z, Pravda D, Modrá H 2012: Metody hematologického vyšetřování ryb (in Czech, Methods of Haematology Examination of Fish). Edice Metodik, FROV JU, Vodňany, No. 122, 38 p.

Watson CF, Baer KN, Benson WH 1989: Dorsal gill incision: A simple method for obtaining blood samples in small fish. Environ Toxicol Chem 8: 457-461

Young T, Walker SP, Alfaro AC, Fletcher LM, Murray JS, Lulijwa L, Symonds J 2019: Impact of acute handling stress, anaesthesia, and euthanasia on fish plasma biochemistry: implications for veterinary screening and metabolomic sampling. Fish Physiol Biochem 45: 1485-1494

Zang L, Shimada Y, Nishimura Y, Tanaka T, Nishimura N 2013: A novel, reliable method for repeated blood collection from aquarium fish. Zebrafish 10: 425-32

Zang L, Shimada Y, Nishimura Y, Tanaka T, Nishimura N 2015: Repeated blood collection for blood tests in adult zebrafish. J Vis Exp 102: e53272 